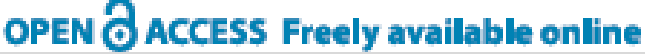

http://www.banglajol.info/index.php/BJID/index

Original Article

Bangladesh Journal of Infectious Diseases

June 2018, Volume 5, Number 1

ISSN (Online) 2411-670X; ISSN (Print) 2411-4820

DOI: http://dx.doi.org/10.3329/bjid.v5i1.37712

\title{
Status of Extended Spectrum Beta-Lactamase (ESBL) Producing Bacteria Isolated from Surgical and Burn Wound at Tertiary Care Hospital in Dhaka City
}

\author{
Mostaqimur Rahman ${ }^{1}$, Hafiza Sultana ${ }^{2}$, Md. Abdullahil Mosawuir ${ }^{3}$, Latifa Akhter ${ }^{4}$, \\ Md. Abdullah Yusuf ${ }^{5}$
}

\begin{abstract}
${ }^{1}$ Assistant Professor, Depart of Microbiology, Rangpur Medical College, Rangpur, Bangladesh; ${ }^{2}$ Assistant Professor, Depart of Microbiology, Rangpur Medical College, Rangpur, Bangladesh; ${ }^{3}$ Associate Professor, Department of Physiology, Rangpur Medical College, Rangpur, Bangladesh; ${ }^{4}$ Assistant Professor, Department of Skin \&VD, Rangpur Medical College, Rangpur, Bangladesh;

${ }^{5}$ Assistant Professor, Department of Microbiology, National Institute of Neuroscience \& Hospital, Dhaka, Bangladesh
\end{abstract}

[Received: 17 March 2018; Accepted: 2 May 2018; Published: 1 June 2018]

\begin{abstract}
s
Background: Surgical and burn wound infection are the most common infection in the hospital settings. Objective: The aim of the present study was to see the status of extended spectrum beta-lactamase (ESBL) producing bacteria isolated from patients presented with surgical and burn wound infection. Methodology: This cross-sectional study was conducted in the Department of Microbiology, BSMMU from January to December 2006, at a period of one year. This study was carried out to detect extended spectrum $\beta$ lactamase producing Gram negative bacteria rapidly by using a kit containing chromogenic cephalosporin directly from primary culture by comparison with phenotypic confirmatory method. Result: Total 181 samples were collected from patients with wound infections of which 170(93.9\%) bacteria were isolated. Among individual samples ESBLs positive strains were highest in surgical wound which was 22(31.42\%) and 24(28.24\%) isolates respectively. From surgical wound swab ESBL was found 3(42.9\%) isolates from Klebsiella species. ESBL producing E. coli was found in 12(35.3\%) isolates. Pseudomonas species showed in $2(22.2 \%)$ isolates and $1(33.3 \%)$ isolate of Acinetobactor species. ESBL positive E. coli was found in $5(45.45 \%)$ isolates from burn wound. ESBL positive Proteus species was detected in 11(28.94\%) isolates from burn wound. Conclusion: Most common bacteria isolated from the infected surgical and burn wound are E. coli and Proteus species, though Klebsiella species is the most common ESBL producing bacteria isolated from both infected surgical and burn wound. [Bangladesh Journal of Infectious Diseases 2018;5(1):21-26]
\end{abstract}

Keywords: ESBL; burn wound; surgical wound; infection

Correspondence: Dr. Md. Mostaqimur Rahman, Assistant Professor, Depart of Microbiology, Rangpur Medical College, Rangpur, Bangladesh; Email: rupom68@yahoo.com

Conflict of interest: There is no conflict of interest to any of the authors of this article.

Funding agency: The study was not funded by any authority.

Contribution to authors: Rahman MM, Sultana H, Mosawuir MA conceived and designed the work, sample collection; Akhter L, Yusuf MA prepared and revised the manuscript.

How to cite this article: Rahman MM, Sultana H, Mosawuir MA, Akhter L, Yusuf MA. Status of Extended Spectrum BetaLactamase (ESBL) Producing Bacteria Isolated from Surgical and Burn Wound at Tertiary Care Hospital in Dhaka City. Bangladesh J Infect Dis 2018;5(1):21-26

Copyright: (02018. Rahman et al. Published by Bangladesh Journal of Infectious Diseases. This article is published under the Creative Commons CC BY-NC License (https://creativecommons.org/licenses/by-nc/4.0/). This license permits use, distribution and reproduction in any medium, provided the original work is properly cited, and is not used for commercial purposes. 


\section{Introduction}

Many genera of Gram negative bacteria possess a naturally occurring, chromosomally mediated $\beta$ lactamase ${ }^{1}$. Being plasmid and transposon mediated has facilitated the spread of these enzymes to other species of bacteria. Within few years after its first isolation, the extended spectrum $\beta$-lactamase spread worldwide and is now found in many different species of members of the family Enterobacteriaceae, Pseudomonas aeruginosa, Haemophilus influenzae and Neisseria gonorrhoeae ${ }^{2}$. $\beta$-lactamases producing bacteria are increasing in number and causing more severe infections, because of their continuous mutation ${ }^{3}$. Extended mutation has led to the emergence of extended spectrum $\beta$-lactamases enzymes, the incidence and types of which vary with geographical location and time. The functional and molecular classifications are complex for the bacteria producing these enzymes. Awareness and detection of these enzymes are necessary for optimal patient care ${ }^{3}$.

Burn patients are infected by hospital-acquired bacteria by various invasive and noninvasive procedures $^{4}$. Early diagnosis of microbial infections and screening for drug resistance is aimed to institute the appropriate antibacterial therapy and to avoid further complications. Now-a-days, majority of the bacteria that cause burn infection in hospitals are resistant to at least one of commonly used drugs $^{5}$. Among the Gram-positive cocci, methicillin-resistant Staphylococcus

aureus (MRSA) is the most important nosocomial pathogen. Sensitivity of MRSA to only a few antibacterial agents limits therapeutic options and poses a threat to the patient life $^{6}$. Extendedspectrum b-lactamases (ESBLs) and metallo-betalactamases (MBLs)-producing organisms pose a major problem for treating burn victims ${ }^{7}$. ESBLs are beta-lactamases capable of conferring bacterial resistance to penicillins, first, second, and thirdgeneration cephalosporins, and aztreonams, but not to cephamycins or carbapenems. $\mathrm{MbL}$ is a group of carbapenem-hydrolyzing b-lactamase but not aztreonams and resists currently available betalactamase inhibitors, but are inhibited by chelating agents such as ethylenediamine tetra-acetic acid $(\text { EDTA })^{8}$.

Again the surgical site infection is also very common. It has played a great role in the morbidity and mortality of the patients ${ }^{9}$. Many bacteria are responsible for this infection. These bacteria are gradually developing resistance to beta-Lactam antibiotics by producing beta-Lactamase ${ }^{10}$. ESBL producing organisms can cause both community and hospital acquired surgical site infections which can be very difficult to treat with common drugs. Isolates may be susceptible to 3rd generation cephalosporin in vitro; however, it results in clinical failure when used in vivo ${ }^{11}$. In this context this present study was undertaken to see the status of extended spectrum beta-lactamase (ESBL) producing bacteria isolated from patients presented with surgical and burn wound infection.

\section{Methodology}

This cross-sectional study was carried out in the Department of Microbiology and Immunology at Banglabandhu Sheikh Mujib Medical University (BSMMU), Dhaka from January 2006 to December 2006 for a period of one (01) year. Samples were collected from in-patient and out-patient department of Dhaka Medical College Hospital, Dhaka and BSMMU, Dhaka after getting informed verbal consent from the patients or from the attendants. Laboratory work was performed in department of Microbiology \& Immunology, BSMMU, Dhaka. $K$. pneumoniae ATCC 700603 (positive control) and E. coli ATCC 25922 (negative control) were used for quality control of ESBL tests (NCCLS, 1999).

Samples were inoculated on appropriate culture media and plates were incubated at $37^{\circ} \mathrm{C}$ aerobically for 24 to 48 hours. Plates were checked for presence of suspected pathogens. All the organisms were identified by their colony morphology, staining characters, pigment production, motility and other relevant biochemical tests as per standard methods ${ }^{8}$. Phenotypic confirmation of ESBLs producing isolates were done by inhibitor potentiated disc diffusion test according to CLSI recommendation.

Third generation cephalosporin i.e. cefotaxime $(30 \mu \mathrm{g})$ and ceftazidime $(30 \mu \mathrm{g})$ disc alone and in combination with clavulanic acid $(10 \mu \mathrm{g})$ were placed on inoculated plate. Mueller Hinton plates were inoculated with test bacteria. Ceftazidime, cefotaxime disc without clavulanic acid was placed on one side of inoculated plate and ceftazidime, cefotaxime disc combined with clavulanic acid was placed on other side of plate. Then the plates were incubated at $35^{\circ} \mathrm{C}$ overnight. After overnight incubation inhibition zone diameter was measured with scale.

It was observed whether there was an increase in zone diameter for cefotaxime and ceftazidime in 
combination with clavulanic acid compared to its zone diameter for cefotaxime and ceftazidime tested alone; thus, $\geq 5 \mathrm{~mm}$ increase in a zone diameter for cefotaxime and ceftazidime in combination with clavulanic acid then the zone diameter of cefotaxime and ceftazidime when tested alone, was confirmed an ESBL producing organism? Genotypic detection of ESBL was performed by plasmid extraction.

\section{Results}

Total 181 samples were collected from patients with wound infections from BSMMU and DMCH of which 87 were surgical wound samples and 94 were burn samples. Total 170(93.9\%) bacteria were isolated from these 181 samples. In infected wound and burn swab majority was yielded culture positive result which were 80(91.9\%) and 90(95.7\%) isolates respectively (Table 1).

Table 1: Rate of Isolation of Bacteria from Surgical and Burn Wound $(\mathrm{N}=181)$

\begin{tabular}{|l|c|c|c|c|}
\hline \multirow{2}{*}{ Types of Sample } & \multicolumn{2}{|c|}{ Culture } & \multirow{2}{*}{ Total } & \multirow{2}{*}{ P value } \\
\cline { 2 - 3 } & Positive & Negative & & \\
\hline Surgical Wound & $80(91.9 \%)$ & $7(8.1 \%)$ & $87(100.0 \%)$ & \multirow{2}{*}{0.000} \\
\hline Burn wound & $90(95.7 \%)$ & $4(4.3 \%)$ & $94(100.0 \%)$ & \\
\hline Total & $\mathbf{1 7 0}(\mathbf{9 3 . 9 \% )})$ & $\mathbf{1 1 ( 6 . 1 \% )}$ & $\mathbf{1 8 1 ( 1 0 0 . 0 \% )}$ & \\
\hline
\end{tabular}

Among 80 culture positive surgical wound swabs $E$. coli was the most common isolated bacteria from surgical wound which was $34(42.5 \%)$ isolates followed by Proteus species, Pseudomonas species, Staph. aureus, Klebsiella species and Acinetobactor species which were $17(21.2 \%)$ isolates, $9(11.3 \%)$ isolates, $9(11.3 \%)$ isolates, $7(8.7 \%)$ isolates and
$3(3.7 \%)$ isolates respectively. However, out of 90 culture positive burn swabs majority bacteria was Proteus species which was $38(42.3 \%)$ isolates followed by Pseudomonas species, E. coli, Klebsiella species, Staph. aureus and Acinetobactor species which were 27(30.0\%) isolates, 11(12.2\%) isolates, $5(5.6 \%)$ isolates, $4(4.4 \%)$ isolates and $3(3.3 \%)$ isolates respectively (Table 2 ).

Table 2: Distribution of different bacterial species among Surgical and Burn Wound $(n=170)$

\begin{tabular}{|l|c|c|c|c|}
\hline \multirow{2}{*}{ Name of Bacteria } & \multicolumn{2}{|c|}{ Wound Swab } & \multirow{2}{*}{ Total } & \multirow{2}{*}{ P value } \\
\cline { 2 - 3 } & Surgical & Burn & & \\
\hline Proteus spp. & $17(21.2 \%)$ & $38(42.3 \%)$ & $55(32.4 \%)$ & \\
\hline Escherichia coli & $34(42.5 \%)$ & $11(12.2 \%)$ & $45(26.5 \%)$ \\
\hline Pseudomonas spp. & $9(11.3 \%)$ & $27(30.0 \%)$ & $36(21.2 \%)$ & \\
\hline Staph. aureus & $9(11.3 \%)$ & $4(4.4 \%)$ & $13(7.6 \%)$ & \multirow{2}{*}{0.000} \\
\hline Klebsiella spp. & $7(8.7 \%)$ & $5(5.6 \%)$ & $12(7.1 \%)$ & \\
\hline Acinetobactor species & $3(3.7 \%)$ & $3(3.3 \%)$ & $6(3.5 \%)$ & \\
\hline Enterococci species & $1(1.3 \%)$ & $1(1.1 \%)$ & $2(1.2 \%)$ & \\
\hline Enterobactor species & $0(0.0 \%)$ & $1(1.1 \%)$ & $1(0.6 \%)$ & \\
\hline Total & $\mathbf{8 0}(\mathbf{1 0 0 . 0 \%})$ & $\mathbf{9 0}(\mathbf{1 0 0 . 0 \% )}$ & $\mathbf{1 7 0}(\mathbf{1 0 0 . 0 \%})$ & \\
\hline
\end{tabular}

Among individual samples ESBLs positive strains were highest in surgical wound which was $22(31.42 \%)$ isolates and from burn wound $24(28.24 \%)$ isolates. Among isolated ESBL producing bacteria Klebsiella species was highest in all types of sample. From culture positive surgical wound swab ESBL was found 3(42.9\%) isolates from Klebsiella species. ESBL producing E. coli was found in $12(35.3 \%)$ isolates. ESBL producing Proteus species was reported in 4(23.5\%) isolates. Pseudomonas species showed in 2(22.2\%) isolates and $1(33.3 \%)$ isolate of Acinetobactor species (Table 3). 
Table 3: ESBLs Producer among Different Species of Bacteria from Culture Positive Surgical Wound Swab $(n=70)$

\begin{tabular}{|l|c|c|c|c|}
\hline \multirow{2}{*}{ Name of Bacteria } & \multicolumn{2}{|c|}{ ESBLs } & \multirow{2}{*}{ Total } & \multirow{2}{*}{ P value } \\
\cline { 2 - 3 } & Positive & Negative & & \\
\hline Escherichia coli & $12(35.3 \%)$ & $22(64.7 \%)$ & $34(100.0 \%)$ & \\
\cline { 1 - 3 } Klebsiella species & $3(42.9 \%)$ & $4(57.1 \%)$ & $7(100.0 \%)$ & \multirow{2}{*}{0.000} \\
\hline Proteus species & $4(23.5 \%)$ & $13(76.5 \%)$ & $17(100.0 \%)$ & \\
\cline { 1 - 3 } Pseudomonas species & $2(22.2 \%)$ & $7(77.8 \%)$ & $9(100.0 \%)$ & \\
\hline Acinetobactor species & $1(33.3 \%)$ & $2(66.7 \%)$ & $3(100.0 \%)$ & \\
\hline Total & $\mathbf{2 2 ( 3 1 . 4 \% )}$ & $\mathbf{4 8}(\mathbf{6 8 . 6 \%})$ & $\mathbf{7 0}(\mathbf{1 0 0 . 0 \%})$ & \\
\hline
\end{tabular}

Klebsiella species were $3(60 \%)$ in infected burn wound. ESBL positive $E$. coli was found in $5(45.45 \%)$ isolates from burn wound. ESBL positive Proteus species was detected in
11(28.94\%) isolates from burn wound. ESBL positive Pseudomonas species was detected in $4(14.81 \%)$ isolates from infected burn wound. ESBL positive Acinetobactor species was found in only $1(33.33 \%)$ isolates (Table 4$)$.

Table 4: ESBLs Producer among Isolated Bacterial Species from Culture Positive Burn Wound Swab $(\mathbf{n}=\mathbf{8 5})$

\begin{tabular}{|l|c|c|c|c|}
\hline \multirow{2}{*}{ Name of Bacteria } & \multicolumn{2}{|c|}{ ESBLs } & \multirow{2}{*}{ Total } & \multirow{2}{*}{ P value } \\
\cline { 2 - 3 } & Positive & Negative & & \\
\hline Escherichia coli & $5(45.5 \%)$ & $6(54.5 \%)$ & $11(100.0 \%)$ & \\
\hline Klebsiella spp. & $3(60.0 \%)$ & $2(40.0 \%)$ & $5(100.0 \%)$ & \multirow{2}{*}{0.000} \\
\hline Proteus spp. & $11(28.9 \%)$ & $27(71.1 \%)$ & $38(100.0 \%)$ & \\
\hline Pseudomonas spp. & $4(14.8 \%)$ & $23(85.2 \%)$ & $27(100.0 \%)$ & \\
\cline { 1 - 3 } Enterobactor spp. & $0(0.0 \%)$ & $1(100.0 \%)$ & $1(100.0 \%)$ & \\
\hline Acinetobactor spp. & $1(33.3 \%)$ & $2(66.7 \%)$ & $3(100.0 \%)$ & \\
\hline Total & $\mathbf{2 4 ( 2 8 . 2 \% )}$ & $\mathbf{6 1 ( 7 1 . 8 \% )}$ & $\mathbf{8 5}(\mathbf{1 0 0 . 0 \%})$ & \\
\hline
\end{tabular}

\section{Discussion}

Bacterial antibiotic resistance has become a major clinical concern worldwide including Bangladesh ${ }^{12}$. Failure to detect these enzymes- ESBLs, AmpC $\beta$ lactamases, Metallo- $\beta$-lactamases has contributed to their uncontrolled spread and therapeutic failure $^{13}$.

Total 181 samples were collected from patients with wound infections from BSMMU and DMCH of which 87 were surgical wound samples and 94 were burn samples. Total 170(93.9\%) bacteria were isolated from these 181 samples. In infected wound and burn swab majority was yielded culture positive result which were $80(91.9 \%)$ and $90(95.7 \%)$ isolates respectively. Among 80 culture positive surgical wound swabs E. coli was the most common isolated bacteria from surgical wound which was
34(42.5\%) isolates followed by Proteus species, Pseudomonas species, Staph. aureus, Klebsiella species and Acinatobactor species which were $17(21.2 \%)$ isolates, $9(11.3 \%)$ isolates, $9(11.3 \%)$ isolates, $7(8.7 \%)$ isolates and $3(3.7 \%)$ isolates respectively. However, out of 90 culture positive burn swabs majority bacteria was Proteus species which was $38(42.3 \%)$ isolates followed by Pseudomonas species, E. coli, Klebsiella species, Staph. aureus and Acinatobactor species which were $27(30.0 \%)$ isolates, $11(12.2 \%)$ isolates, $5(5.6 \%)$ isolates, $4(4.4 \%)$ isolates and $3(3.3 \%)$ isolates respectively. Similar to the present study Rahman et $\mathrm{al}^{14}$ in Bangladesh found $33 \%$ E.coli, $27 \%$ Klebsiella species in an urban hospital.

Among different samples, isolation rate of E.coli was highest $34(42.5 \%)$ in surgical wound and $11(12.22 \%)$ in burn wound. Klebsiella spp. was 
found $7(8.75 \%)$ isolates in surgical wound and 5 $(5.55 \%)$ in burn wound. Proteus spp. was highest in burn wound $(42.22 \%)$ followed by surgical wound (21.25\%). Pseudomonas species was highest in burn wound $(30.0 \%)$ followed by surgical wound (11.25\%). Staph aureus was found highest in surgical wound $9(11.2 \%)$ followed by burn wound $4(4.4 \%)$.

Isolation rate of different strains among surgical wound sample showed highest rate in E. coli (42.5\%) followed by Proteus species (21.25\%), Pseudomonas species (11.25\%), Staph. aureus $(11.25 \%)$, Klebsiella species $(8.75 \%)$. In a study of pus samples Rahman et al. (2004) found Staph. aureus (36\%), E. coli (32\%), Klebsiella species (24\%). Isolation rate of different strains among burn wound sample showed highest rate in Proteus spp. $38(42.22 \%)$, followed by Pseudomonas spp. 27(30\%), E. coli 11(12.22\%), Klebsiella spp. 5(5.55\%), Staph. aureus 4 (4.44\%). In a study Pseudomonas aeruginosa was found as the highest isolated bacteria from burn patients (12.5\%) followed by Enterobacter species (2.6\%), E coli $(1.4 \%)$, Klebsiella species $(0.8 \%)$ and Proteus species $(0.2 \%)^{15}$. In another study at BSMMU, ESBL was detected in $23.19 \%$ Gram negative bacteria, among them Klebsiella species was highest( $40.90 \%)$ followed by Proteus spp. (40.62\%), E.coli (26.92\%) and less in Pseudomonas spp. $(4.87 \%)^{16}$. In another study at urban hospital in Dhaka showed $(43.21 \%)$ E. coli and $(39.5 \%)$ Klebsiella species as ESBL producers ${ }^{14}$.

ESBL producing strains were isolated from surgical wound and burn wound. Highest rate of ESBLs $(32.33 \%)$ was found in surgical wound $(31.42 \%)$ and in burn wound (28.24\%). Among isolated ESBL producing bacteria Klebsiella species was highest in all types of sample. Among surgical wound strains E. coli (35.3\%), Klebsiella species (42.9\%), Proteus species (23.5\%), Pseudomonas species (22.2\%), Acinetobactor species (33.3\%) were ESBLs producers. Among burn wound strains E. coli (45.45\%), Klebsiella species (60.0\%), Proteus species (28.9\%) and Pseudomonas species (14.81\%) and Acinetobactor species (33.3\%) were ESBLs producers. Higher rate was also found in surgical wound $(31.43 \%)$ followed by burn wound $(28.24 \%)$. This may be due to most of the patients were post-operative with improper handling of wound, overcrowding, understaffing or nursing workload with cross-transmission of ESBL producing Enterobacteriaceae ${ }^{15}$.

The isolation rate of ESBL producing Klebsiella spp. was highest among burn wound (60\%), followed by surgical wound (42.86\%). Similar higher rate ESBL producing strain s of Klebsiella spp. (44\%) also observed in Singapore hospital ${ }^{16}$. In the study by Rahman et $\mathrm{al}^{14}$ ESBL producer Klebsiella pneumoniae was highest in pus (54.5\%). Klebsiella spp. has the ability to spread rapidly in hospital environment and tends to cause nosocomial outbreak ${ }^{17}$.

ESBL producing Proteus spp. was observed in 16 $(27.11 \%)$ out of total 59 samples of which highest rate was observed in burn wound $28.94 \%$, probably due to high rate of isolation from burn unite. Multi drug resistant Pseudomonas spp. also found in burn unite. Increase number of ESBLs producer is probably due to previously treated with $\beta$-lactam drugs, extreme ages, bed retention, immune suppuration, association with other diseases, temporary or permanent urinary catheter ${ }^{18}$. In a study in BSMMU it was also found lower rate of Pseudomonas species (4.9\%) ESBLs producer ${ }^{12}$. Lower rate of ESBL producing Pseudomonas is due to Pseudomonas spp. exhibits multiple mechanism of drug resistance simultaneously other than $\mathrm{ESBL}^{19}$, such as AmpC $\beta$-lactamase enzymes, and Metallo $\beta$-lactamase. These enzymes are resistant to clavulanic acid that is used to detect ESBL producing bacteria in double disc and phenotypic method $^{20}$.

\section{Conclusion}

In conclusion most common bacteria isolated from the infected surgical and burn wound are E. coli and Proteus species. However, the most common ESBL producing bacteria is Klebsiella species isolated from both infected surgical and burn wound. Proper detection of ESBL producing bacteria should be performed from the infected surgical and burn wound.

\section{References}

1. Bennett JW, Robertson JL, Hospenthal DR, Wolf SE, Chung KK, Mende K, Murray CK. Impact of extended spectrum betalactamase producing Klebsiella pneumoniae infections in severely burned patients. J Am Coll Surg 2010;211(3):391-9 2. Peirano G, van Greune $\mathrm{CH}$, Pitout JD. Characteristics of infections caused by extended-spectrum $\beta$-lactamaseproducing Escherichia coli from community hospitals in South Africa. Diagn Microbio Infect Dis 2011;69(4):449-53.

3. Sasirekha B, Manasa R, Ramya P, Sneha R. Frequency and antimicrobial sensitivity pattern of extended spectrum $\beta$ lactamases producing E. coli and Klebsiella pneumoniae isolated in a tertiary care hospital. Al Ameen J Med Sci 2010;3(4):265-71

4. Freeman JT, Nimmo J, Gregory E, Tiong A, De Almeida M, McAuliffe GN, Roberts SA. Predictors of hospital surface contamination with Extended-spectrum $\beta$-lactamase-producing Escherichia coli and Klebsiella pneumoniae: patient and 
organism factors. Antimicrobial resistance and infection control. 2014;3(1):5

5. Ake J, Scott P, Wortmann G, Huang XZ, Barber M, Wang Z, Nikolich M, Van Echo D, Weintrob A, Lesho E. Gramnegative multidrug-resistant organism colonization in a US military healthcare facility in Iraq. Infect Cont Hosp Epidem 2011;32(06):545-52

6. Kumarasamy KK, Toleman MA, Walsh TR, Bagaria J, Butt $\mathrm{F}$, Balakrishnan $\mathrm{R}$, et al. Emergence of a new antibiotic resistance mechanism in India, Pakistan, and the UK: a molecular, biological, and epidemiological study. Lancet Infect Dis 2010;10(9):597-602

7. Owlia P, Azimi L, Gholami A, Asghari B, Lari AR. ESBLand MBL-mediated resistance in A. baumannii: a global threat to burn patients. Infez Med 2012;20(3):182-7

8. Bowler PG, Welsby S, Towers V, Booth R, Hogarth A, Rowlands V, et al. Multidrug-resistant organisms, wounds and topical antimicrobial protection. Internat Wound $\mathrm{J}$ 2012;9(4):387-96

9. Kunz AN, Brook I. Emerging resistant Gram-negative aerobic bacilli in hospital-acquired infections. Chemother 2010;56(6):492-500

10. Rogers BA, Aminzadeh Z, Hayashi Y, Paterson DL. Country-to-country transfer of patients and the risk of multiresistant bacterial infection. Clin Infect Dis 2011;53(1):49-56

11. Rastogi V, Nirwan PS, Jain S, Kapil A. Nosocomial outbreak of septicaemia in neonatal intensive care unit due to extended spectrum $\beta$-lactamase producing $K$. pneumoniae showing multiple mechanisms of drug resistance. Indian J Med Microbiol 2010;28(4):380

12. Karim S, Ahmed S, Parvez M, Mottalib M, Islam AH, Rahman M, Haq JA. Emerging multi-drug resistant organisms in a tertiary care hospital of Dhaka City. Bangladesh J Med Sci. 2002;8(1):53-7.
13. Shiju MP, Yashavanth R, Narendra N. Detection of extended spectrum beta-lactamase production and multidrug resistance in clinical isolates of E. coli and K. pneumoniae in Mangalore. J Clin Diag Res 2010;4(3):2442-5

14. Rahman M, Haq J A, Hossain M A, Sultana R, Islam F, Islam S. Prevalence of extended-spectrum $\beta$-lactamaseproducing Escherichia coli and Klebsiella pneumoniae in an Urban hospital in Dhaka, Bangladesh. Antimicrobial Agents 2004;24: 508-510.

15. Altoparlak U, Erol S, Aklay M N, Celebi F and Kadanali A, 2004. Time related changes of antimicrobial resistance patterns and predominant bacterial profiles of burn wounds and body flora of burned patients. BURNS 2004; 30(7): 660-664

16. Alim R. Detection of extended spectrum $\beta$-lactamase (ESBL) producing bacteria. Thesis 2005. BSMMU

17. Mahmoud AB, Zahran WA, Hindawi GR, Labib AZ, Galal R. Prevalence of multidrug-resistant Pseudomonas aeruginosa in patients with nosocomial infections at a university hospital in Egypt, with special reference to typing methods. J Virol Microbiol 2013;13

18. Leung GH, Gray TJ, Cheong EY, Haertsch P, Gottlieb T. Persistence of related bla-IMP-4 metallo-beta-lactamase producing Enterobacteriaceae from clinical and environmental specimens within a burns unit in Australia-a six-year retrospective study. Antimicrobial Resist Infect Contr 2013;2(1):35

19. Peshattiwar PD, Peerapur BV. ESBL and MBL mediated resistance in Pseudomonas aeruginosa: An emerging threat to clinical therapeutics. J Clin Diagn Res 2011;5:1552-4

20. Bashir D, Thokar MA, Fomda BA, Bashir G, Zahoor D, Ahmad S, Toboli AS. Detection of metallo-beta-lactamase (MBL) producing Pseudomonas aeruginosa at a tertiary care hospital in Kashmir. African J Microbiol Res 2011;5(2):164-72 